\title{
Multiobjective Mathematical Programming Model for the Optimization of End-of-Life Buildings' Deconstruction and Demolition Processes
}

\author{
Dimitrios Aidonis \\ Department of Logistics, Technological Education Institute of Central Macedonia, 60100 Katerini, Greece; \\ daidonis@teicm.gr; Tel.: +30-6972-871-947
}

Received: 5 February 2019; Accepted: 1 March 2019; Published: 7 March 2019

\begin{abstract}
Nowadays, construction and demolition waste management has become a critical process for the construction industry, as the specific waste stream poses important environmental issues and challenges. In the case of dismantling end-of-life buildings, the selection of the appropriate technique between deconstruction and conventional demolition is a critical decision affecting the total volume and type of produced waste. Toward this effect, in this paper, a novel decision-making model for the optimization of end-of-life buildings' deconstruction and demolition processes is proposed. The objective of the proposed model is the simultaneous and weighted optimization of the total cost and time for the completion of the deconstruction and demolition processes, taking into consideration economic, legislative, and environmental criteria. Finally, a demonstration of the application of the proposed model is presented via two specific case studies and by discussing a few interesting managerial insights.
\end{abstract}

Keywords: deconstruction; demolition; decision-making; optimization

\section{Introduction}

In the past years, the main objective of the construction industry has been the optimal management of construction works in order to reduce the total cost of the process and increase a system's profitability. During the 1980s, emphasis was placed by the construction industry on the use of and mainly on the maintenance of buildings, as buildings and structures were facing serious problems due to a lack of previous maintenance [1]. In recent years, after 2000, the construction industry has focused on the design stage, as well as on the construction and demolition works of end-of-life (EOL) buildings/structures, taking into consideration certain environmental issues. The most important environmental issue deals with the optimal management of generated construction and demolition $(C \& D)$ waste. This major change was due to increased environmental awareness of people, as C\&D waste is one of the most voluminous waste streams generated worldwide. In the case of the European Union, this waste stream accounts for approximately one-third of all generated waste [2]. To this end, the European Union developed the Waste Framework Directive 2008/98/EC [3] for C\&D waste management. According to Article 11.2, by 2020, there is an objective of $70 \%$ of reuse and recycling of C\&D waste by all member states.

The change to friendlier environmental C\&D waste management is also evidenced by the rapid growth of publications of scientific papers addressing the significant environmental impacts of this waste stream, as well as options reuse and recycling of C\&D waste management [4-6].

The type and total amount of the produced C\&D waste depends mainly on the following heterogeneous factors: (i) Type and size of building/structure, (ii) year of construction, (iii) place of construction, and (iv) construction and deconstruction techniques employed. 
As for EOL buildings, dismantling techniques play an important role in the production and management of C\&D waste [7]. Until the 1950s, the main technique for dismantling end-of-life construction was deconstruction by hand [8,9]. Today, alternative dismantling techniques have been developed due to the rapid development of technology and equipment in the construction industry. In particular, the basic techniques applied to the dismantling of EOL buildings are deconstruction and conventional demolition. In general, mechanical equipment used in alternative dismantling techniques of EOL buildings makes processes safer and less time-consuming [10].

Conventional demolition involves the execution of works aimed at the permanent demolition of a building in a short period of time using mechanical equipment. The most common method of conventional demolition is referred to in the literature as the "top-down" method. As indicated by the name of the method, demolition works take place on a vertical upward axis. In other words, demolition work begins with the dismantling of the roof and is completed on the ground, demolishing the building floor by floor [11]. The "top-down" method is ideal for the demolition of buildings located in densely populated areas where access to heavy-duty machinery is difficult [12].

Deconstruction can be defined as the dismantling method of EOL buildings/structures in order to achieve the safe removal and disposal of hazardous materials and to maximize the reuse and recycling of the remaining materials [13,14]. The process of deconstruction of a building can be characterized as the reverse of its construction process $[15,16]$. In other words, the last building material placed during the construction works of the building is the first to be removed during the performance of the deconstruction process. Nowadays, deconstruction tends to replace conventional demolition strategies due to rising sustainability issues and economic benefits from the recovery of the building materials [17].

There are papers in the existing literature that have examined the basic principles and main differences between the demolition techniques of EOL buildings [18-20]. Economic issues, such as operational costs, labor costs, and transportation costs during the implementation of demolition techniques, have also been examined [21,22]. Interesting aspects under study have dealt with the environmental impacts of deconstruction and conventional demolition techniques [23-25]. Multicriteria analysis applications have been identified in literature reviews for decision-making related to the integrated management of the waste generated during the demolition phase. In Reference [10], the authors presented a decision support system using multicriteria analysis to select the best demolition technique for buildings, while in Reference [26], an applied multicriteria analysis using the PROMETHEE II method for decision-making on the choice of optimal building demolition and waste management was presented.

A significant part of existing research in the field of C\&D waste management has dealt with the development and implementation of an integrated plan for the management of deconstruction and demolition processes. More specifically, research efforts have focused on the theoretical approach of the problem through the development of a management plan for the waste generated and the management of $C \& D$ waste in the demolition phase of an EOL building. Regarding the development of quantitative methods for the management of C\&D waste, the majority of research efforts have examined the calculation of the total amount of waste generated either during the construction phase or during the demolition phase, as well as the cost analysis of the implementation of the selected processes. There is a gap in the literature, as only a few research papers have examined quantitative techniques for the optimization of end-of-life buildings' deconstruction and demolition processes.

The main goal of the paper is to present the development of a multiobjective mathematical programming model for the optimization of deconstruction and demolition processes (Section 2). The applicability of the proposed model, through two specific case studies, is illustrated in Section 3. Finally, in Section 4, the main conclusions of this paper are provided. 


\section{System Description}

\subsection{Problem Definition}

Decision-making related to the optimization of the deconstruction and demolition processes of end-of-life buildings has emerged as an important research field for both the academy and the market. In practice, in many cases, demolition contractors initially perform selective deconstruction by recovering building materials with high reuse and recycle levels and high resale values. Then, they perform demolition work on the rest of the structure. Thus, the determination of the optimal deconstruction depth is related to C\&D materials. In any case, there are two critical factors for the final decision: (i) Total cost and (ii) total time for the completion of the process. Total execution time significantly impacts the overall management of the dismantling project and affects the planning and execution of other activities of the contractor. In the real world, the execution of demolition processes ensures the reduction of total costs and time in comparison to deconstruction processes. However, taking into account possible legislative/environmentally friendly constraints associated with the management of EOL building materials, it is easy to understand that the selection of the appropriate dismantling technique of a specific structure can be defined as a highly complex multicriteria problem.

In this subsection, the development of a multiobjective mathematical programming model for the optimization of deconstruction and demolition processes is presented. The proposed mathematical model is a mixed integer linear programming model for one product (which refers to the building/structure), multiple elements (which refers to EOL building components and materials), and one time period. The objective of the proposed model is the simultaneous and weighted optimization of the total costs and time for the completion of the deconstruction and demolition processes, taking into consideration economic, legislative, and environmental criteria.

The decision-making process is directly related to the bill of materials (BOM) of the structure and includes the selection of the most appropriate process (deconstruction or demolition) at each stage of the work, the recovery of specific building materials, as well as the optimal management of all produced C\&D materials (Figure 1).

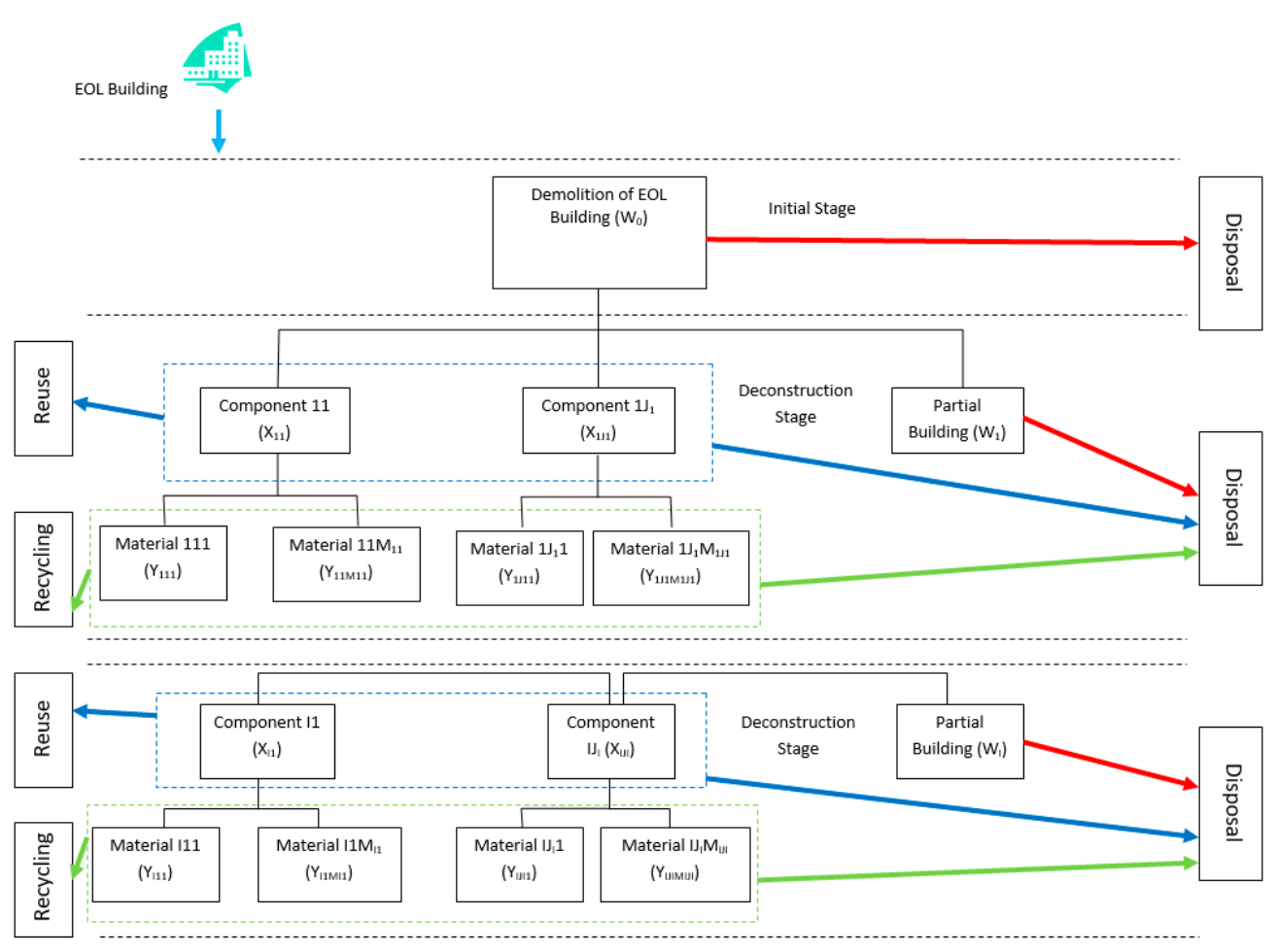

Figure 1. Flow diagram of deconstruction or demolition options for an end-of-life (EOL) building. 
The selection of the deconstruction process at each stage provides the possibility of recovering structural components, which can either be reused or dismantled into building materials. These materials, depending on their composition and quantity, can be recycled or disposed of. In the case of demolition, the produced building materials are treated as mixed rubble.

\subsection{System Assumptions}

In this subsection, the economic and technological assumptions involved in the development of the mathematical model are presented. In particular, the main assumptions are summarized as follows:

- The contractor is responsible both for the execution of the deconstruction or demolition processes and the recovery management of the C\&D materials;

- In every deconstruction stage, the contractor may not recover all of the building materials before proceeding to demolition work on the rest of the building;

- The total costs of the deconstruction and demolition processes involve variable and fixed costs of producing and recovering EOL building components and materials;

- In some cases, mainly in deconstruction processes, the contractor may have revenues from the sale of specific EOL components and materials;

- During the deconstruction or demolition phase, the operational costs for a specific task are independent of its volume or size. This means that in the proposed mathematical model, economies of scale are not taken into consideration;

- The demolition process and waste handling costs are constant per ton of produced materials and irrespective of the stage of the demolition of the EOL building;

- The sequence of deconstruction processes is subject to specific technological constraints. For example, the recovery of roof skeleton materials first requires the removal of roofing material;

- As for the total execution time of dismantling the EOL building, there is an assumption that all the deconstruction works of the building are executed sequentially, without the possibility of performing parallel tasks.

\subsection{Model Formulation}

First, the employed indices/sets are provided:

- $\quad i=0, \ldots, I$ : Deconstruction and demolition stages. The value $i=0$ refers to the case of demolition work of the entire building;

- $j=1, \ldots, J_{i}$ : Structural components in the $i$ th deconstruction stage, with $I \in\{1, \ldots, I\}$;

- $m=0, \ldots, M_{i j}$ : Materials resulting from disassembling the $j$ th structural component at the $i$ th deconstruction stage, with $i \in\{1, \ldots, I\}$;

- $k=0, \ldots, 1$ : Alternative ways of managing the produced materials. The value $k=0$ refers to the final deposition, and the value $k=1$ refers to the recycling of building materials.

In Table 1, the general, cost, and time parameters of the model are provided. 
Table 1. General parameters.

\begin{tabular}{|c|c|c|}
\hline \multicolumn{2}{|c|}{ Parameter } & Description \\
\hline \multirow{9}{*}{ General } & $w_{i j}^{x}$ & $\begin{array}{c}\text { Weight of the } j \text { th structural component available at the } i \text { th } \\
\text { deconstruction stage (tons) }\end{array}$ \\
\hline & $w_{i j m 1}^{z}$ & $\begin{array}{l}\text { Weight of the } m \text { th end material available from the } j \text { th structural } \\
\text { component at the } i \text { th deconstruction stage (tons) }\end{array}$ \\
\hline & $T W$ & Total weight of structural elements and end materials (tons) \\
\hline & $e$ & $\begin{array}{c}\text { Minimum desired deconstruction ratio of the total weight of each EOL } \\
\text { building, for recovery purposes }(\%)\end{array}$ \\
\hline & $P_{1}$ & Value of objective function 1 \\
\hline & $P_{2}$ & Value of objective function 2 \\
\hline & $P_{3}$ & Value of objective function 3 \\
\hline & $b_{1}$ & Coefficient of objective function $P_{1}$ \\
\hline & $b_{2}$ & Coefficient of objective function $P_{2}$ \\
\hline \multirow{7}{*}{ Cost } & $r^{w}$ & Potential revenues from selling demolition waste ( $€ /$ ton $)$ \\
\hline & $r_{i j}^{x}$ & $\begin{array}{c}\text { Potential revenues from selling the } j \text { th structural component, collected } \\
\text { at the } i \text { th deconstruction stage ( } € / \text { ton })\end{array}$ \\
\hline & $r_{i j m k}^{z}$ & $\begin{array}{l}\text { Potential revenues from final disposal ( } k=0 \text { for deposition and } k=1 \text { for } \\
\text { recycling) of the } m \text { th end material, collected from the } j \text { th structural } \\
\text { component at the } i \text { th deconstruction stage }(€ / \text { ton })\end{array}$ \\
\hline & $c^{w}$ & Demolition process and waste handling costs ( $€ /$ ton $)$ \\
\hline & $c_{i j}^{x}$ & $\begin{array}{l}\text { Deconstruction and handling costs, in order to gain the } j \text { th structural } \\
\text { component from the } i \text { th deconstruction stage }(€ / \text { ton })\end{array}$ \\
\hline & $c_{i j m}^{y}$ & $\begin{array}{l}\text { Deconstruction and handling costs, in order to gain the } \underline{m} \text { th end } \\
\text { material from the } j \text { th structural component at the } i \text { th deconstruction } \\
\text { stage }(€ / \text { ton })\end{array}$ \\
\hline & $c_{i j m k}^{z}$ & $\begin{array}{c}\text { Disposal ( } k=0 \text { for deposition and } k=1 \text { for recycling) costs of the } \underline{m} \text { th } \\
\text { end material from the } j \text { th structural component at the } i \text { th deconstruction } \\
\text { stage }\end{array}$ \\
\hline \multirow{3}{*}{ Time } & $t^{w}$ & $\begin{array}{l}\text { Total time required for demolition process and waste management } \\
\text { (hours/ton) }\end{array}$ \\
\hline & $t_{i j}^{x}$ & $\begin{array}{l}\text { Total time required in order to gain the } j \text { th structural component from } \\
\text { the } i \text { th deconstruction stage (hours/ton) }\end{array}$ \\
\hline & $t_{i j m}^{y}$ & $\begin{array}{l}\text { Total time required in order to gain the } m \text { th end material from the } j \text { th } \\
\text { structural component at the } i \text { th deconstruction stage (hours/ton) }\end{array}$ \\
\hline
\end{tabular}

In Table 2, the decision variables of the mathematical model are provided.

Table 2. Decision variables.

\begin{tabular}{cc}
\hline Variable & Description \\
\hline$W_{i}$ & $\begin{array}{c}\text { Boolean variable denoting the } i \text { th stage until which the deconstruction process takes } \\
\text { place, while the remaining building is demolished }\left(\mathrm{e} . \mathrm{g} ., W_{0}=1 \text { entails demolition of }\right. \\
\text { the entire building structure, and alternatively } W_{3}=1 \text { entails that deconstruction } \\
\text { continues until the third stage, when the rest of the building is demolished }) \\
\text { Boolean variable denoting whether the } j \text { th structural component at the } i \text { th } \\
\text { deconstruction stage will be recovered }\left(X_{i j}=1\right) \text { or not }\left(X_{i j}=0\right)\end{array}$ \\
$X_{i j}$ & $\begin{array}{c}\text { Boolean variable denoting whether the } m \text { th end material of the } j \text { th structural } \\
\text { component at the } i \text { th deconstruction stage will be recovered }\left(Y_{i j m}=1\right) \text { or not }\left(Y_{i j m}=0\right) \\
\text { Boolean variable denoting whether the } m \text { th end material of the } j \text { th structural }\end{array}$ \\
$Z_{i j m k}$ & $\begin{array}{c}\text { component at the } i \text { th deconstruction stage will be recycled }\left(Z_{i j m 1}=1\right) \text { or deposited } \\
\left.\text { ( } Z_{i j m 0}=0\right)\end{array}$ \\
$\mathrm{Q}$ & Minimax decision variable
\end{tabular}


Consequently, the multiobjective binary linear programming model is formulated. Maximize $P_{1}$ :

$$
\begin{gathered}
\left(r^{w}-c^{w}\right) \cdot\left(T W-\sum_{i=1}^{I} \sum_{j=1}^{J_{i}} w_{i j}^{x} \cdot X_{i j}-\sum_{i=1}^{I} \sum_{j=1}^{J_{i}} \sum_{m=1}^{M_{i j}} w_{i j m}^{y} \cdot Y_{i j m}\right. \\
\left.-\sum_{i=1}^{I} \sum_{j=1}^{J_{i}} \sum_{m=1}^{M_{i j}} \sum_{k=o}^{1} w_{i j m k}^{z} \cdot Z_{i j m k}\right) \\
+\sum_{i=1}^{I} \sum_{j=1}^{J_{i}}\left(r_{i j}^{x}-c_{i j}^{x}\right) \cdot X_{i j}-\sum_{i=1}^{I} \sum_{j=1}^{J_{i}} \sum_{m=1}^{M_{i j}} c_{i j m}^{y} \cdot Y_{i j m}+ \\
\sum_{i=1}^{I} \sum_{j=1}^{J_{i}} \sum_{m=1}^{M_{i j}} \sum_{k=0}^{1}\left(r_{i j m k}^{z}-c_{i j m k}^{z}\right) \cdot Z_{i j m k} .
\end{gathered}
$$

Minimize $P_{2}$ :

$$
\begin{aligned}
t^{w} \cdot\left(T W-\sum_{i=1}^{I} \sum_{j=1}^{J_{i}}\right. & \left.w_{i j}^{x} \cdot X_{i j}-\sum_{i=1}^{I} \sum_{j=1}^{I_{i}} \sum_{m=1}^{M_{i j}} w_{i j m}^{y} \cdot Y_{i j m}\right) \\
& +\sum_{i=1}^{I} \sum_{j=1}^{J_{i}} t_{i j}^{x} \cdot X_{i j}+\sum_{i=1}^{I} \sum_{j=1}^{J_{i}} \sum_{m=1}^{M_{i j}} t_{i j m}^{y} \cdot Y_{i j m},
\end{aligned}
$$

s.t.

$$
\begin{gathered}
\sum_{i=0}^{I} W_{i}=1, \\
W_{i}+X_{d n}+Y_{d n o} \leq 1, \forall i=0, \ldots, I-1, \\
\forall d=i+1, \ldots, I, \forall n=1, \ldots, J_{d}, \forall 0=1, \ldots, M_{d n} \\
Y_{i j m}=Y_{i j, m+1}, \forall i=1, \ldots, I, \forall j, \forall m=1, \ldots, M_{i j}-1, \\
Y_{i j m}=\sum_{k=0}^{1} Z_{i j m k}, \forall i=1, \ldots, I, \forall j, \forall m, \\
X_{d n} \leq X_{i j}+Y_{i j m}, \forall i=1, \ldots, I-1, \forall j, m, \forall d=I+1, \ldots, I, \forall n=1, \ldots, J_{d}, \\
Y_{d n o} \leq X_{i j}+Y_{i j m}, \forall i=1, \ldots, I-1, \forall j, m, \\
\forall d=I+1, \ldots, I, \forall n=1, \ldots, J_{d}, \forall 0=1, \ldots, M_{d n} \\
\sum_{i=1}^{I} \sum_{j=1}^{I_{i}} w_{i j}^{x} \cdot X_{i j}+\sum_{i=1}^{I} \sum_{j=1}^{I_{i}} \sum_{m=1}^{M_{i j}} w_{i j m}^{y} \cdot Y_{i j m}+\sum_{i=1}^{I} \sum_{j=1}^{I_{i}} \sum_{m=1}^{M_{i j}} w_{i j m 1}^{z} \cdot Z_{i j m 1} \geq e \cdot W, \\
X_{i j}, Y_{i j m}, Z_{i j m k} \in\{0,1\} .
\end{gathered}
$$

The objective function aims at simultaneous and weighted maximization of the total profit $\left(P_{1}\right)$ and minimization of the total execution time $\left(P_{2}\right)$ of the reverse supply chain processes for deconstruction and demolition waste management. To this effect, multiple groups of constraints were considered. More specifically, the first group of constraints, Equations (3)-(6), are the network configuration constraints, ensuring the feasibility and the optimality of the resulting solution. Equation (3) dictates that the deconstruction of an end-of-life structure can proceed to a specific optimal depth, while for the rest of the structure, the demolition processes take place. Inequality (4) ensures that components and materials of a specific deconstruction stage cannot be removed if at a previous stage the building was demolished, while Equation (5) denotes that the components and materials at any deconstruction stage are recovered (materials are produced from the dismantling of the structural components). Moreover, Equation (6) ensures that in the case of structural components being recovered at any deconstruction stage, then all the materials produced by the disassembly of a particular component are recovered. The second group of constraints, Equations (7)-(8), are the classical technological constraints / precedence relationships in a deconstruction project. More specifically, Inequalities (7) and (8) ensure the order of execution of deconstruction processes, as they set the conditions for the recovery of the components and materials. Inequality (9) plays the role of an environmental constraint 
or a constraint posed by legislation that enforces a lower bound on the ratio of the total weight from each EOL structure that should be deconstructed for recovery purposes (either reuse or recycling). Finally, Equation (10) contains binary constraints.

\subsection{Solving Methodology}

The solving methodology of the multiobjective mathematical programming model consists of three stages and is briefly analyzed below [27]:

Step 1: Determine the target values of objective functions by solving each objective function with all the constraints individually;

Stage 2: Determine the weights for each objective function;

Step 3: Develop and resolve the revised model.

The objective function, Equation (11), aims at minimizing the continuous $Q$ (minimax) decision variable:

$$
\text { Minimize } P_{3}: Q
$$

s.t.

$$
\begin{gathered}
\sum_{i=0}^{I} W_{i}=1, \\
W_{i}+X_{d n}+Y_{d n o} \leq 1, \forall i=0, \ldots, I-1, \\
\forall d=i+1, \ldots, I, \forall n=1, \ldots, J_{d}, \forall 0=1, \ldots, M_{d n} \\
Y_{i j m}=Y_{i j, m+1}, \forall i=1, \ldots, I, \forall j, \forall m=1, \ldots, M_{i j}-1, \\
Y_{i j m}=\sum_{k=0}^{1} Z_{i j m k}, \forall i=1, \ldots, I, \forall j, \forall m, \\
X_{d n} \leq X_{i j}+Y_{i j m}, \forall i=1, \ldots, I-1, \forall j, m, \forall d=I+1, \ldots, I, \forall n=1, \ldots, J_{d}, \\
Y_{d n o} \leq X_{i j}+Y_{i j m}, \forall i=1, \ldots, I-1, \forall j, m, \\
\forall d=I+1, \ldots, I, \forall n=1, \ldots, J_{d}, \forall 0=1, \ldots, M_{d n} \\
\sum_{i=1}^{I} \sum_{j=1}^{J_{i}} w_{i j}^{x} \cdot X_{i j}+\sum_{i=1}^{I} \sum_{j=1}^{J_{i}} \sum_{m=1}^{M_{i j}} w_{i j m}^{y} \cdot Y_{i j m}+\sum_{i=1}^{I} \sum_{j=1}^{J_{i}} \sum_{m=1}^{M_{i j}} w_{i j m 1}^{z} \cdot Z_{i j m 1} \geq e \cdot W, \\
b_{1} \cdot\left(\frac{P_{1}-\text { target value } P_{1}}{\text { target value } P_{1}}\right) \leq Q, \\
b_{2} \cdot\left(\frac{P_{2}-\text { target value } P_{2}}{\text { target value } P_{2}}\right) \leq Q, \\
Q \in \mathbb{R}^{+} X_{i j}, Y_{i j m}, Z_{i j m k} \in\{0,1\} .
\end{gathered}
$$

The group of constraints Equations (12)-(18) are the same as the group of constraints Equations (3)-(9). Inequalities (19) and (20) represent the weighted percentage deviation of the value of the objective functions $P_{1}$ and $P_{2}$, respectively, from the target value. The deviation must not be greater than the value of the continuous variable $Q$. Finally, in Equation (21), the trivial non-negativity and binary constraints are provided.

\section{Case Study}

In the framework of the numerical investigation of the proposed mathematical model, the dismantling processes of two EOL buildings (a residential building and an industrial building) located in Thessaloniki, Northern Greece, were examined. The overall goal was to demonstrate the applicability of the proposed model while further obtaining managerial insights into the properties of the optimal solution. In Table 3, the main characteristics of the two EOL buildings are provided. 
Table 3. Main characteristics of the EOL buildings.

\begin{tabular}{ccc}
\hline Characteristics & $\begin{array}{c}\text { Residential Building } \\
\text { (Case Study 1) }\end{array}$ & $\begin{array}{c}\text { Industrial Building } \\
\text { (Case Study 2) }\end{array}$ \\
\hline Year of construction & 1970 & 1985 \\
Type of construction & Reinforced concrete & Metallic \\
Number of floors & 4 & 1 \\
Floor area $\left(\mathrm{m}^{2}\right)$ & 130 & 450 \\
Total height $(\mathrm{m})$ & 12.50 & 6.20 \\
Roof type & Tile roof & Metal roof panels \\
Heating type & Boiler & Cooling and heating units \\
Floor coverings & Ceramic tiles & Plastic tiles \\
Windows & Wood & Aluminum \\
\hline
\end{tabular}

In Table 4, the typical sequence of dismantling activities for both EOL buildings (Case Studies 1 and 2) is presented [28,29].

Table 4. EOL components per deconstruction stage.

\begin{tabular}{|c|c|c|}
\hline \multirow[b]{2}{*}{ Deconstruction Stage } & \multicolumn{2}{|c|}{ Components } \\
\hline & $\begin{array}{l}\text { Residential Building } \\
\text { (Case Study 1) }\end{array}$ & $\begin{array}{l}\text { Industrial Building } \\
\text { (Case Study 2) }\end{array}$ \\
\hline \multirow{7}{*}{1} & Heating devices & Heating devices \\
\hline & Heating components & Heating components \\
\hline & Doors & Doors \\
\hline & Windows & Windows \\
\hline & Sanitary devices & Sanitary devices \\
\hline & Shutters & Shutters \\
\hline & Electrical devices & Electrical devices \\
\hline \multirow{3}{*}{2} & Floor covering & Floor covering \\
\hline & Roof covering & Roof covering \\
\hline & Wall covering & Wall covering \\
\hline \multirow{4}{*}{3} & Electrical installations & Electrical installations \\
\hline & Sanitary & Sanitary \\
\hline & Plumbing & Plumbing \\
\hline & Heating & Heating \\
\hline 4 & Roof frame & Roof frame \\
\hline \multirow{2}{*}{5} & Walls & Walls \\
\hline & Insulation materials & Insulation materials \\
\hline \multirow{4}{*}{6} & Floors & \multirow{4}{*}{ Metal stairs } \\
\hline & Stairs & \\
\hline & Reinforced concrete walls & \\
\hline & Foundation & \\
\hline \multirow[b]{2}{*}{7} & \multirow[b]{2}{*}{-} & Floors \\
\hline & & Metal skeleton \\
\hline 8 & - & Foundation \\
\hline
\end{tabular}

A basic parameter of the problems under consideration was the recovery rate of EOL building components and materials, as this greatly affects the optimal solution. For both case studies, a total of five different problems were solved by choosing different combinations for the coefficients $\left(b_{1}\right.$ and $\left.b_{2}\right)$ of the objective functions $P_{1}$ and $P_{2}$ and setting the recovery rate of the building materials equal to zero $(e=0)$. The first case study (residential building) optimization model consisted of 1 continuous variable, 83 binary variables, and 222 constraints, while the second case study (industrial building) optimization model consisted of 1 continuous variable, 79 binary variables, and 201 constraints. Both 
case studies were solved on a Pentium 4 computer with $3.6 \mathrm{GHz}$ CPU and 1 GB RAM via the CPLEX ${ }^{\circledR}$ v.9.1 solver and through the mathematical programming language AMPL ${ }^{\circledR}$. The computational time was a few seconds for a variety of generated problem instances, and thus the solution performance of the proposed model was quite satisfactory.

Tables 5 and 6 summarize the values of the objective functions, the deconstruction stage, and the recovery components and materials for each case study. In order to obtain useful managerial insights and conclusions, a sensitivity analysis was conducted with the use of different values (five different scenarios for each case study) for coefficients $b_{1}$ and $b_{2}$. In the cases where a coefficient equaled $100 \%$, this meant that the related factor (total cost or total time) was critical.

Table 5. Results of Case Study 1.

\begin{tabular}{cccccccc}
\hline A/A & Coefficient & $\begin{array}{c}\text { Value } \boldsymbol{P}_{\mathbf{1}} \\
(\boldsymbol{\epsilon})\end{array}$ & $\begin{array}{c}\text { Value } \boldsymbol{P}_{\mathbf{2}} \\
\mathbf{( h \mathbf { h } )}\end{array}$ & Value $\boldsymbol{P}_{\mathbf{3}}$ & Stage & $\begin{array}{c}\text { Structural } \\
\text { Components }\end{array}$ & Materials \\
\hline 1 & $\begin{array}{c}b_{1}=100 \% \\
b_{2}=0 \%\end{array}$ & $-20,629.4$ & 355 & 0.208 & 1 & $\begin{array}{c}\text { Electrical devices } \\
\text { Heaters, boilers }\end{array}$ & - \\
2 & $\begin{array}{c}b_{1}=75 \% \\
b_{2}=25 \%\end{array}$ & $-20,629.4$ & 355 & 0.156 & 1 & $\begin{array}{c}\text { Electrical devices } \\
\text { Heaters, boilers }\end{array}$ & - \\
3 & $\begin{array}{c}b_{1}=50 \% \\
b_{2}=50 \%\end{array}$ & $-20,629.4$ & 355 & 0.104 & 1 & $\begin{array}{c}\text { Electrical devices } \\
\text { Heaters, boilers }\end{array}$ & - \\
4 & $\begin{array}{c}b_{1}=25 \% \\
b_{2}=75 \% \\
b_{1}=0 \% \\
5\end{array}$ & $-20,717.3$ & 342.5 & 0.052 & 0 & - & - \\
\hline
\end{tabular}

Table 6. Results of Case Study 2.

\begin{tabular}{|c|c|c|c|c|c|c|c|}
\hline $\mathbf{A} / \mathbf{A}$ & Coefficient & $\begin{array}{l}\text { Value } P_{1} \\
(€)\end{array}$ & $\begin{array}{c}\text { Value } P_{2} \\
(h r)\end{array}$ & Value $P_{3}$ & Stage & $\begin{array}{c}\text { Structural } \\
\text { Components }\end{array}$ & Materials \\
\hline 1 & $\begin{array}{c}b_{1}=100 \% \\
b_{2}=0 \%\end{array}$ & $-13,661.5$ & 310.5 & 0.229 & 2 & $\begin{array}{l}\text { Electrical devices } \\
\text { Cooling and heating } \\
\text { units, roof panels }\end{array}$ & $\begin{array}{c}\text { Aluminum, } \\
\text { glass, } \\
\text { plastic }\end{array}$ \\
\hline 2 & $\begin{array}{l}b_{1}=75 \% \\
b_{2}=25 \%\end{array}$ & $-13,709.4$ & 225 & 0.036 & 1 & $\begin{array}{c}\text { Electrical devices } \\
\text { Cooling and heating } \\
\text { units }\end{array}$ & $\begin{array}{c}\text { Aluminum, } \\
\text { glass }\end{array}$ \\
\hline 3 & $\begin{array}{l}b_{1}=50 \% \\
b_{2}=50 \%\end{array}$ & $-13,742.1$ & 217 & 0.005 & 1 & $\begin{array}{c}\text { Electrical devices } \\
\text { Cooling and heating } \\
\text { units }\end{array}$ & - \\
\hline 4 & $\begin{array}{l}b_{1}=25 \% \\
b_{2}=75 \%\end{array}$ & $-13,796$ & 212 & 0.074 & 0 & - & - \\
\hline 5 & $\begin{array}{c}b_{1}=0 \% \\
b_{2}=100 \%\end{array}$ & $-13,796$ & 212 & 0 & 0 & - & - \\
\hline
\end{tabular}

Summarizing the conclusions, it can be stated that when the recovery rate of components and materials equaled zero, then the total cost and the total execution time were two targets competing between themselves. In the case where the reduction of the total cost was the only objective, the deconstruction process was active in early stages with the recovery of certain structural components and materials. On the other hand, in the case where the total time was the only objective, the demolition process was the best practice. Finally, a useful conclusion was related to the value of the environmental parameter $e$, which represents the minimum desired deconstruction ratio of the total weight of each EOL building, for recovery purposes (\%). The value of parameter $e$ is defined by the relevant regulatory frameworks and constitutes the key decision driver in these environments. According to the analysis, higher values of parameter $e$ resulted in a simultaneous increase in the total cost and total execution time of the system. 


\section{Conclusions}

Nowadays, C\&D waste management of EOL buildings possesses serious environmental issues in the construction industry. The selection of the appropriate dismantling technique of EOL buildings can be considered to be a complex decision-making process including economic, legislative, and environmental criteria. To this end, decision-makers must consider two basic practices for dismantling EOL buildings. The first practice involves the demolition of the entire structure, while the second practice deals with the selective deconstruction of the structure in order to maximize the reuse and recycling of the remaining components and materials. There is a last option of performing selective deconstruction at early stages of the dismantling process and then performing demolition work on the rest of the structure. In the real world, there are two critical factors for the final decision: (i) Total cost and (ii) total time for the completion of the process. In this paper, a novel integrated model for supporting the decision-making process and dealing with the optimal selection of the dismantling technique of EOL buildings was presented. The objective of the proposed model is the simultaneous and weighted optimization of the total costs and time for the completion of the deconstruction and demolition processes of a single EOL building with multiple components and materials and a single time period. On the whole, the proposed approach contributes toward a comprehensive and integrated strategy for the selection of the right dismantling processes of EOL buildings. Problems that appear to have great future research merit include problems studying the stochasticity of the considered general, cost, and time parameters. An additional future research direction could include environmental impact as an extra critical factor for the final decision apart from the total cost and total time for the completion of the process. To this end, the author intends to develop a new holistic multiobjective model, focusing also on specific environmental, technological, and economic issues.

Funding: The author wishes to acknowledge financial support provided by the Special Account for Research Funds of the Technological Education Institute of Central Macedonia, Greece, under grant AMF/LG/060219-22/01.

Conflicts of Interest: The author declares no conflicts of interest.

\section{References}

1. Itoh, Y.; Liu, C. Lifecycle Management Approach for Network-Level Transportation Infrastructure Systems Based on Information Technologies. In INCITE 2000: Implementing IT to Obtain a Competitive Advantage in the 21st Century; The Hong Kong Polytechnic University Press: Hong Kong, China, 2000; pp. 300-314.

2. European Commission. EU Construction \& Demolition Waste Management Protocol; European Commission: Brussels, Belgium, 2016; pp. 1-46.

3. The European Parliament and the Council of the European Union, Directive 2008/98/EC on waste and repealing certain Directives. Available online: https://eur-lex.europa.eu/legal-content/EN/TXT/?uri= CELEX:32008L0098 (accessed on 21 January 2019).

4. Faleschini, F.; Zanini, M.A.; Pellegrino, C.; Pasinato, S. Sustainable management and supply of natural and recycled aggregates in a medium-size integrated plant. Waste Manag. 2016, 49, 146-155. [CrossRef] [PubMed]

5. Hossain, U.; $\mathrm{Ng}$, S.T. Influence of waste materials on buildings' life cycle environmental impacts: Adopting resource recovery principle. Resour. Conserv. Recycl. 2019, 142, 10-23. [CrossRef]

6. Vitale, P.; Arena, N.; Di Gregorio, F.; Arena, U. Life cycle assessment of the end-of-life phase of a residential building. Waste Manag. 2017, 60, 311-321. [CrossRef] [PubMed]

7. Xanthopoulos, A.; Aidonis, D.; Vlachos, D.; Iakovou, E. A planning optimisation framework for construction and demolition waste management. Int. J. Industrial Syst. Eng. 2012, 10, 257-276. [CrossRef]

8. Roodman, D.; Lenssen, N. A Building Revolution: How Ecology and Health Concerns are Transforming Construction; Worldwatch Institute: Washington, DC, USA, 1999.

9. Gordon Engineering. Demolition Energy Analysis of Office Building Structural Systems; Athena Sustainable Materials Institute: Ottawa, ON, Canada, 1997.

10. Abdullah, A.; Anumba, C.J. Decision Model for the Selection of Demolition Techniques. Adv. Build. Technol. 2002, 1, 1671-1679. 
11. Poon, C.S.; Yu, A.T.W.; Ng, L.H. On-site sorting of construction and demolition waste in Hong Kong. Resources. Conserv. Recycl. 2001, 32, 157-172. [CrossRef]

12. Kourmpanis, B.; Papadopoulos, A.; Moustakas, K.; Stylianou, M.; Haralambous, K.J.; Loizidou, M. Preliminary Study for the Management of Construction and Demolition Waste. Waste Manag. Res. 2008, 26, 267-275. [CrossRef] [PubMed]

13. Goldstein, G. Waste Not, Want Not. Architecture 2003, 88, 131-141.

14. Bruening, S.; Chini, A. Deconstruction and Materials Reuse, An. International Overview, Final Report of Task Group 39 on Deconstruction; CIB Publication: Delft, The Netherlands, 2004.

15. Greer, D. Building the Deconstruction Industry. Biocycle 2004, 45, 36-42.

16. Queheille, E.; Taillandier, F.; Saiyouri, N. Optimization of strategy planning for building deconstruction. Autom. Constr. 2019, 98, 236-247. [CrossRef]

17. Akbarnezhad, A.; Ong, K.C.G.; Chandra, L.R. Economic and environmental assessment of deconstruction strategies using building information modelling. Autom. Constr. 2014, 37, 131-144. [CrossRef]

18. von Stein, E.L.; Savage, G.M. Current Practices and Applications in Construction and Demolition Debris Recycling. Res. Recycl. 1994, 13, 85-94.

19. Anumba, C.; Abdullah, A.; Fesseha, T. Selection of Demolition Techniques: A Case Study of the Warren Farm Bridge. Struct. Surv. 2003, 21, 36-48. [CrossRef]

20. Liu, C.; Pun, S.K.; Langston, C. A Preliminary Study on Building Demolition Engineering and Management. World Trans. Eng. Technol. Education 2005, 4, 201-207.

21. Chau, C.K.; Xu, J.M.; Leung, T.M.; Ng, W.Y. Evaluation of the impacts of end-of-life management strategies for deconstruction of a high-rise concrete framed office building. Appl. Energy 2017, 185, 1595-1603. [CrossRef]

22. Ghisellini, P.; Ripa, M.; Ulgiati, S. Exploring environmental and economic costs and benefits of a circular economy approach to the construction and demolition sector: A literature review. J. Clean. Prod. 2018, 178, 618-643. [CrossRef]

23. Akinade, O.O.; Oydele, L.O.; Ajayi, S.O.; Bilal, M.; Alaka, H.A.; Owolabi, H.A.; Bello, S.A.; Jaiyeoba, B.E.; Kadiri, K.O. Design for Deconstruction (DfD): Critical success factors for diverting end-of-life waste from landfills. Waste Manag. 2017, 60, 3-13. [CrossRef] [PubMed]

24. Silva, R.V.; De Brito, J.; Dhir, R.K. Properties and composition of recycled aggregates from construction and demolition waste suitable for concrete production. Constr. Build. Mater. 2014, 65, 201-217. [CrossRef]

25. Coelho, A.; De Brito, J. Influence on construction and demolition waste management on the environmental impact of buildings. Waste Manag. 2012, 32, 532-541. [CrossRef] [PubMed]

26. Kourmpanis, B.; Papadopoulos, A.; Moustakas, K.; Kourmoussis, F.; Stylianou, M.; Loizidou, M. An Integrated Approach for the Management of Demolition Waste in Cyprus. Waste Manag. Res. 2008, 26, 573-581. [CrossRef] [PubMed]

27. Ragsdale, C. Spreadsheet Modeling and Decision Analysis: A Practical Introduction to Management Science, 3rd ed.; South-Western College Publishing: Nashville, TN, USA, 2001.

28. Spengler, T.; Püchert, H.; Penkuhn, T.; Rentz, O. Environmental Integrated Production and Recycling Management. Eur. J. Oper. Res. 1997, 97, 308-326. [CrossRef]

29. Aidonis, D.; Xanthopoulos, A.; Vlachos, D.; Iakovou, E. An analytical methodological framework for managing reverse supply chains in the construction industry. WSEAS Trans. Environ. Dev. 2008, 11, 1036-1046.

(C) 2019 by the author. Licensee MDPI, Basel, Switzerland. This article is an open access article distributed under the terms and conditions of the Creative Commons Attribution (CC BY) license (http:/ / creativecommons.org/licenses/by/4.0/). 